\title{
Investigating Practical Measures to Reduce Power Outages and Energy Curtailments
}

\author{
Abdullah M. Al-Shaalan \\ EE Department, College of Engineering, King Saud University, Riyadh, KSA \\ Email: shaalan@ksu.edu.sa, shaalan123@gmail.com
}

How to cite this paper: Al-Shaalan, A.M. (2017) Investigating Practical Measures to Reduce Power Outages and Energy Curtailments. Journal of Power and Energy Engineering, 5, 21-36.

https://doi.org/10.4236/jpee.2017.511003

Received: October 9, 2017

Accepted: November 20, 2017

Published: November 23, 2017

Copyright $\odot 2017$ by author and Scientific Research Publishing Inc. This work is licensed under the Creative Commons Attribution International License (CC BY 4.0).

http://creativecommons.org/licenses/by/4.0/

\begin{abstract}
This work attempts to investigate some practical measures that may reduce severe power outages that lead to energy curtailments. The first step of this attempt is to explore, from the consumer's perspective, the adverse effects of the energy curtailments that reflect enormous damages (tangible and intangible) to the residential sector in the city of Riyadh (the capital of the Kingdom of Saudi Arabia). The second step is to propose, analyze, and employ energy conservation strategies that lead to both energy conservation and costs savings. The study results show that some customers will suffer enormous tangible and intangible losses should these outages occur during specific times, seasons, and for prolonged durations. In order to reduce these power outages and hence mitigate their adverse effects and consequences, the study proposes proper practical measures and solutions without compromising the consumers' needs, satisfaction, and convenience.
\end{abstract}

\section{Keywords}

Power Outages, Energy Curtailment, Cost, Consumer, Energy Conservation

\section{Introduction}

Electric energy curtailments occur when the available system capacity, due to severe power outages, is insufficient to meet the consumer's loads requirements. These capacity deficits which lead to energy curtailments are particularly critical at sites where the environment and public safety are at risk. Institutions such as hospitals, sewage treatment plants, water reservoirs, airports, public places, etc., usually have backup power sources, such as standby generators, which will automatically start up when electric power is lost. Other critical systems, such as telecommunications and computer facilities are also required to have emergency 
power sources. Telephone exchange rooms usually have uninterrupted power supply (UPS) (arrays of lead-acid batteries) for backup and a socket for connecting a generator during extended periods of outage. During these events of system deficits, energy shortages costs will be borne by the electric company and by its customers. The company curtailments costs include loss of revenues and increased expenses of repair and maintenance. The company costs usually form only a small part of the total curtailments costs while the greater part is that borne by the customers.

The problem of assessing an energy curtailment's impact upon consumers depends on many factors and situations as well as the perceived effects of a curtailment when consumers are deprived of their electric energy needs during critical moments. There are diverse classes of consumers whereby each will tolerate loss of service differently. To the residential user, for instance, curtailment of the production process usually incurs great losses that can be alleviated by some means of early warning systems, available standbys, or compensations. For the commercial consumer, the curtailment occurrence may cause inconvenience when he is either forced to close until power is restored or operate using his own alternative means. Such curtailments are especially worrying for food freezers in supermarkets, medicines in pharmacies, etc. For the residential consumer, curtailments that cause distress, discomfort, and anxiety come as a result of disruption of domestic activities, loss of leisure, food spoilage, and health hazards. Moreover, residential consumers must endure a great deal of hardship when curtailments occur during evenings, hot summer days, the Holy month of Ramadan, etc.

The difficulty associated with estimating residential losses, resulting from severe power outages, is due to the fact that the activities pertaining to this sector are not productive and most of its outputs are consumed within the household premises and thereby cannot be valued in the market. Curtailments may interfere with housekeeping activities such as cooking, washing, vacuum cleaning, and disrupt the use of refrigerators, air conditioners, lighting, computers, game consoles, entertainment systems as well as negatively affect ceremonial gatherings and social events etc. More seriously, such disruptions may compromise the health of vulnerable individuals. Therefore, residential consumers may incur tangible losses such as food spoilage and paying extra expenses and intangible losses in terms of inconvenience, discomfort, anxiety, and frustration.

The residential sector in Riyadh city has been selected as a practical case to conduct this study. Located in the central region of the Kingdom of Saudi Arabia, Riyadh is the largest and fastest growing metropolis in terms of population, economy, and infrastructure within the Saudi Electric Company.

The status of this research is firstly, aiming at investigating and analyzing the adverse tangible and intangible effects of the unexpected power outages causing energy curtailments. The second step is to propose, analyze, and employ energy conservation strategies that lead to both energy conservation and costs savings. 
In this regard, both survey and mathematical model will be implemented.

\section{Review of Selected Existing Studies}

In [1], the authors presented a framework and review of customer outage costs based on extensive analysis and results of electric utility outage cost surveys.

In [2], the authors provided empirical data that tested the relationship between energy consumption and income per capita, at the household level. They determined that at high levels of net energy consumption, increasing gross energy consumption may cause power outages which can be avoided by switching to more efficient energy sources.

In [3], the authors discussed the massive electric power outages that occurred in the northeastern United States on August 14-15, 2003. They estimated the losses associated with that severe power outages affecting residential consumers for longer durations. They concluded that losses increased in a nonlinear manner with curtailment duration.

In [4], the authors utilized a practical radial distribution system database in the development of an individual consumer sector and established a composite consumer damage function for a diverse class of consumers. The main objective of the paper was to assess reliability cost-worth indices of expected energy not served (EENS), expected cost of curtailments (ECOI), and interrupted energy assessment rate (IEAR) of a typical radial practical distribution system using a generalized analytical technique. The results presented in this paper can be useful for the electric power companies, designers, and planners in the decisionmaking process.

In [5], the author used a survey that evaluated how far households were "willing-to-pay" in order to avoid unexpected curtailments in electricity service. In this survey, the author used a statistical approach that was defined as a function of household characteristics, outage attributes, and outages history. He showed that losses estimation is sensitive to the interaction of attributes of previously experienced and hypothetical curtailments.

In [6], the author discussed the issue of energy efficiency and conservation in the residential sector and showed that energy efficiency can be targeted to reduce peak demand, leading to a significant fuel savings at a time when supply is constrained.

In [7], the author developed a web-based tool that addresses direct as well as indirect energy requirements. By means of a simple expert system, participants could attain options and feedback on energy reduction. This tool was tested in Groningen city (the Netherlands) with a sample of 300 households, resulting in a direct and indirect energy reduction of about $31 \%$ compared to total energy consumption.

In [8], the author used energy-conservation programs that focused on the residential sector with more understanding on how the variables that affected household energy conservation lead to more-effective consumer energy conser- 
vation. In this study, mail questionnaires were sent to 2000 Ventura County residents randomly selected from the Hayne's telephone directory. There were 500 returned questionnaires yielding a response rate of $25 \%$. Results indicated that home-owners adopted significantly more efficiency measures than renters. Respondents favored local energy-conservation policies that required no personal action.

In [9], the author described energy-conservation campaigns that were applied at two military installations where residents did not pay their own energy charges. Before-and-after energy use was measured and residents were surveyed about their energy consumption behaviors. Residents mentioned that they were motivated by the desire to do the right thing, set a good example for their children and have a comfortable home. These studies may have implications for other situations where residents are not charged for individual energy use, including other government-subsidized facilities, master-metered apartments, and hotels.

In [10], the author developed a model that explained household choice of electricity conservation modes. The model was based on the premise that households would adopt those conservation modes that yielded benefits greater than perceived costs. The author found that households differed in the conservation modes they adopted. High-income households were more likely to implement expenditure-intensive methods, while low-income households were more likely to adopt time-intensive conservation methodologies. The results suggested a possible explanation as to why high-income families and residents of single-detached homes saved the largest (absolute) amount of energy. A popular explanation was that these households consumed the most energy, and thus would be most likely to benefit.

In [11], the authors evaluated energy conservation methods for the residential sector by employing a model that simulated city-scale energy consumption within the residential sector by considering the diversity of household and building types. In this model, all the households in the city are classified into 380 categories based on the household and building type. The accuracy of the model was verified by comparing its results with the statistical and the measured data on Osaka City, Japan. Various types of energy conservation measures planned by the Japanese government for the residential sector are simulated and their effects on Osaka City are evaluated quantitatively.

In [12], the author reviewed and evaluated the effectiveness of interventions aimed at encouraging households to reduce energy consumption. Thirty-eight studies performed within the field of social and environmental psychology were reviewed, and categorized as involving either antecedent strategies (i.e. commitment, goal setting, data, and modeling) or consequence of strategies (i.e. feedback, rewards, incentives, and information). Rewards and incentives have effectively encouraged energy conservation, but with rather short-lived effects. Feedback has also proven its merits, in particular, when it is given frequently.

In [13], the author stated that the Korean household sector was responsible 
for about $60 \%$ of the country's primary energy requirement. He also indicated that increases in household consumption expenses were responsible for a relatively high growth of energy consumption. He concluded that switching to consumption of less energy intensive products and decrease in energy intensities of products contributed substantially to reduce the increase in total household energy consumption.

In [14], the author showed that energy conservation measures on buildings have a significant role to play in reducing the burden of the energy bill on the Lebanese economy. This study showed that the residential sector was the main area where energy measures could be applied. Such measures included the use of insulation materials, double-glazed windows, shading, efficient air-conditioning systems, and energy-saved lamps. It was demonstrated through detailed energy analysis of typical residential and office buildings that strict conservation was beneficial on both the micro- and macro-economic levels.

In [15], the author performed modeling of energy consumption by residential sectors of 20 Japanese cities modeled at the city-scale and the model, households were classified into 228 categories based on the family size and building type. $\mathrm{He}$ evaluated the effectiveness of energy conservation measures, such as improving energy efficiency of home appliances, improving heat insulation of buildings, and changing preset temperature. In addition, he also discussed and demonstrated differences in energy saving effects between some chosen cities.

In [16], the author measured the thermal behaviors of specimens and an upgraded prototype residential building. This work showed that the proposed insulation system can save up to $50 \%$ of the energy through it. Also, field surveys indicated the ability for the retrofitted residential dwellings to meet the requirements set by the Ministry of Construction in China in terms of energy conservation. This retrofitted practice presented in this study is generally accepted as an example that will influence both commercially and environmentally nearly 90 percent of the total existing buildings in cold regions of China.

In [17], the authors presented a detailed analysis based on customers interruption cost due to constrained distribution networks. They showed the extensive cost that the customers will endure due to unexpected outages and energy curtailment.

In [18], A Spanish consultant firm conducted an extensive study for the large electric company in the Kingdom of Saudi Arabia to evaluate the impacts and effects of power outages and energy shortages upon the state national economy, and suggested practical solutions to reduce these outages and mitigate their losses and costs.

In [19], A study was conducted in Korea that showed a comparison between consumers who can accept lower reliability in exchange for lower bills and consumers who reject the reliability reduction with high outages occurrences.

In [20], this paper proposes a method that based on home load control (HLC) to manage the operation periods of responsive and nonresponsive electrical ap- 
pliances considering various customer preferences. It determines several recommended operation periods for nonresponsive appliances. The customer preferences are in the format of payment cost, interruption cost, and different operational constraints.

In [21], the theoretical model presented here suggests that the principal cost of power outages to residential electricity consumers is the loss of leisure, while the marginal value of leisure equals the household's net income earning rate. Results of a Brazilian survey supported this hypothesis and revealed activity patterns in urban households.

In [22], the authors presented a development of load models at the appliance level. These include conventional controllable loads such as space cooling/heating, water heater, washing machine, clothes dryer. Validation of the appliancelevel load models is carried out by comparing the models' output with the real electricity consumption data for the associated appliances. The appliance-level load models are aggregated to generate load profiles for a distribution circuit, which are validated against the load profiles of an actual distribution circuit. The demand response load models can be used to study changes in electricity consumption both at the household and the distribution network levels.

In [23], the paper analyzes the importance of estimating the value of service reliability for electric utility customers. The electricity outage cost is estimated for residential and commercial category of customers in ten districts of a northern Indian state of Rajasthan as a case study. To obtain responses from the customers a survey questionnaire is framed containing issues related to quality of power supply, outage cost, customer's desire to have an uninterrupted power supply, compensation for increased outages and choice of alternative actions to avoid or mitigate the effects of outages. The outage cost is calculated by two approaches, namely, preparatory action approach and contingent value approach. Results of this study are meaningful from the utility's perspective in order to ensure the adequate service continuity and customer satisfaction.

\section{Work Objective and Proposed Methodology}

After reviewing and scrutinizing all the existing works involving various modeling techniques, approaches and methodologies, the author believes that there are some gaps to be filled and shortcomings to be extended in those preceding works. For instance, the authors assessed the energy conservation in the residential sector without explicitly considering it as a hedge against power outages and a remedy to energy ceases and curtailments. Hence, it is the Author's impression, that there was little attention given to the advantageous and rewarding correlation between coherent energy conservation and least outages occurrences, Hence, the first step of this endeavor is to explore, from the consumer's perspective, the adverse effects of the energy curtailments that reflect enormous damages (tangible and intangible) to the residential sector in the city of Riyadh (the capital of the Kingdom of Saudi Arabia). The second step is to propose, analyze, 
and employ energy conservation strategies that lead to both energy conservation and costs saving. To fulfill these two essential steps, the following processes have been established:

A consumer survey has been used in order to yield practical and definite results that can estimate the real impact of energy shortages upon the residential sector. It is the author's opinion that the most suitable estimation of outages occurrences and their impacts is the consumer's own assessment. Based on his personal perception to negative consequences during power outages and his level of preparedness or willingness-to-pay, he may go to great lengths to avoid such outages or, at least, mitigate their effects. This approach is theoretically more pertinent to the perception of the residential consumer and his needs.

\section{Residential Income vs. Electricity Consumption}

The basic unit for analyzing residential consumption was the average household of five persons which was considered to be approximately constant over all income classes and was also assumed to remain unchanged in the future [Saudi Statistics Department, 2017]. Using the income data and average monthly consumption from the residential survey in Riyadh city, it was possible to plot the graph (shown in Figure 1) reflecting the strong and positive correlation between the electric energy consumption and household income which agrees with the fundamental premise that energy consumption at the household level is a key indicator of increasing income and standard of living.

\section{Consumers' Hardship vs. Outages Occurrences in Various Seasons}

The survey postulates some hypothetical scenarios of frequent service interruptions in different seasons of the year between 12 noon and $11 \mathrm{pm}$. The survey

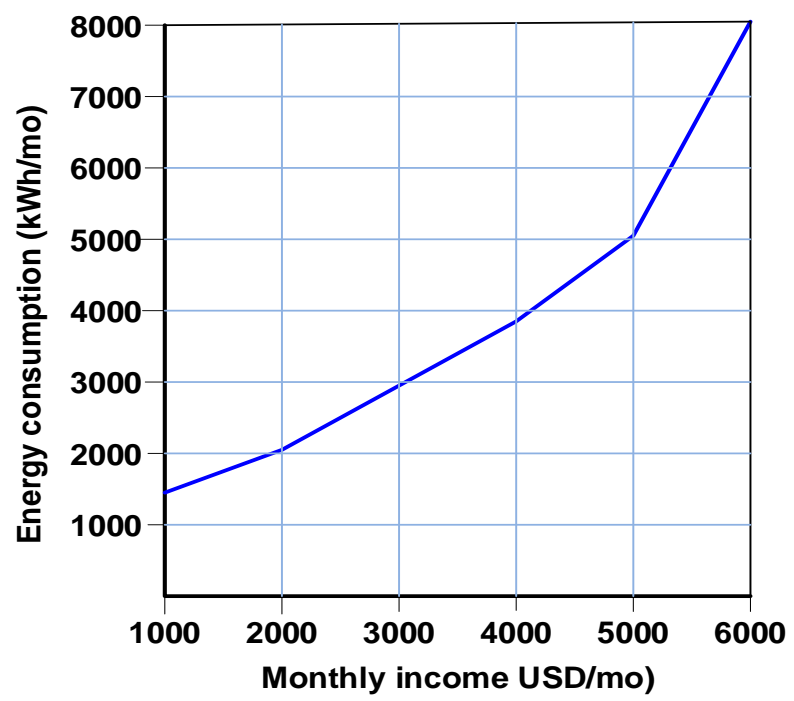

Figure 1. Consumers' monthly income vs. monthly energy consumption. 
outcome is shown in Figure 2 which indicates that the lost energy impact is more pronounced in summer season, in a country like Saudi Arabia, com-pared with other seasons due to the high temperature and extensive use of air-conditioners accordingly which constitutes the largest share in the energy consumed by the customers in that country.

\section{Variation of Outages Cost with Outage Duration}

The average value of the maximum amount per month that the respondents were willing to pay for less severe outages (interruptions) occurrences is based on their average monthly energy consumptions (kWh/mo.) and payments (\$/mo.) in summer time. The cost per outage estimation for the residential sector as $\$ / \mathrm{kWh}$ was evaluated for the purpose of this study and also to be easily and conveniently compared with other similar time durations studies. This estimate is shown in Table 1 and portrayed in Figure 3, which demonstrate clearly the time-dependent and the non-linear nature of the outages cost that reach prohibitive limits should interruptions last and extended for longer durations.

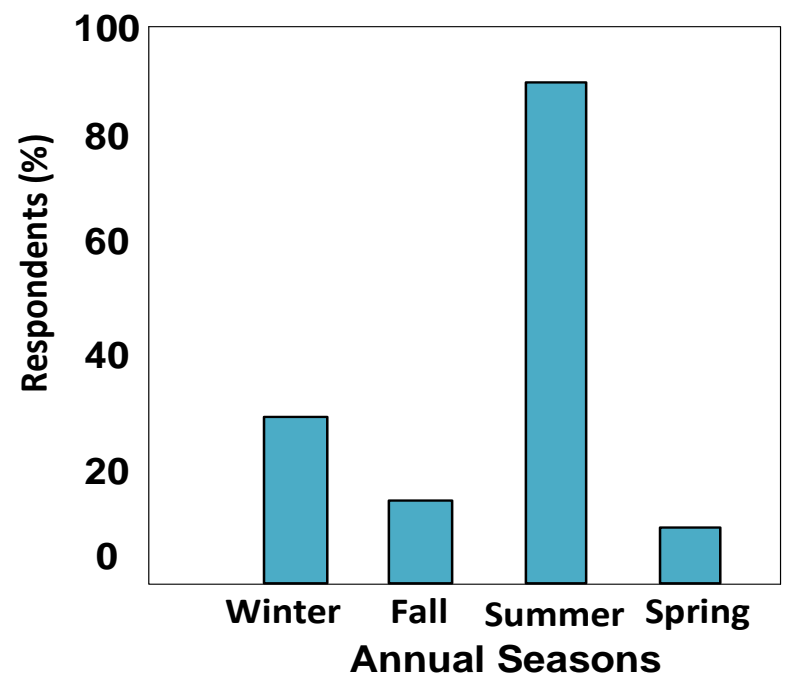

Figure 2. Consumers' monthly income vs. monthly energy consumption.

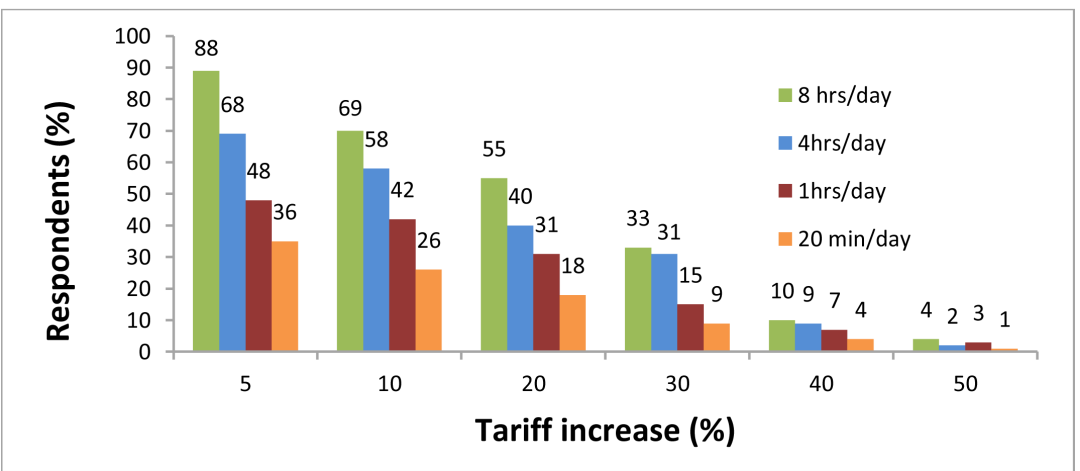

Figure 3. Suggested tariff rate increase with outage durations. 
Table 1. Variation of outages cost with outage duration.

\begin{tabular}{ccc}
\hline Outage durations & Survey prediction & Model prediction \\
\hline 20 min. & 0.33 & 0.46 \\
1 hour & 0.36 & 0.98 \\
4 hours & 0.97 & 9.76 \\
8 hours & 60.40 & 98.10 \\
\hline
\end{tabular}

\section{Cost Estimation Based on Consumer's Perception and Willingness-to-Pay}

Most outages effects that are discussed in many of the published works are intangible and cannot be assessed in terms of monetary values. The appropriate question to ask, therefore, is: "What set of preparations and precautions should a consumer adopt as a criterion to ensure both supply continuity and quality worth? The answer depends on practical and theoretical structure of the analyses. In general, it is the author's opinion that one of the most suitable estimation of reliability worth is the consumer's preparatory actions during outages and his "Willingness-to-Pay" to avert their adverse and undesirable impacts. This approach is practically sound and more related to the perception of the residential consumer and to his energy requirements. Therefore, in order to seek the consumers' readiness and the types of preparatory actions he intends to undertake against possible power outages and energy curtailments, questionnaires have been prepared and sent to selected samples of consumers representing various classes of the society. Respondents are directed to imagine a hypothetical situation where their local electric company announces unexpected power outages that will occur daily during Summer time for various durations. They are then asked to predict which action(s) they might take in preparation for the outages. The costs quoted in the list of actions are used to estimate the cost of preparations that respondents indicate that they are willing to undertake to avert or, at least, mitigate the adverse effects of the outages. Also, the survey aims to explore the extent to which they are willing to pay to avert service cessation. Therefore, it is suggested that the power system has become subject to more frequent power outages. To increase system reliability, the company may add generating units and/or reinforce its network facilities which may result in tariff increase. Hence, the question postulates daily power outages during the Summer period for durations of 20 minutes, 1 hour, 4 hours, and 8 hours (these time durations have been globally adopted and agreed upon for convenient comparison between various cases in different places). A range of possible tariff rate increases is proposed and the consumers are asked to perceive and appraise the possible damage resulting from service curtailments and consequently discern appropriate tariff rate increases based on its prevailing present structure. The data reported by the respondents are exhibited by Figure 3. The questionnaires results show that a significant number of respondents are willing to pay a higher rate for even up to $30 \%$ above the cost of the normal charge to avoid prolonged outages durations. 
The willingness-to-pay, however, becomes less when more rate increase is suggested or less frequent outages are proposed.

\section{Effect of Early Warning and Standby Availability in Mitigating Outages Costs}

With the likelihood of power outages that may occur from the supplier side due to previously intended repairs or scheduled maintenance purposes but not due to unexpected severe outages, early warnings from the supplier (local electric company) ought to be sent to its customers in advance to tell which parts of the grid and when will be running short of power due to maintenance, repair or for any other intended purposes. This action will certainly assist the consumer to prepare himself with other substitute facilities or postpone some of his domestic activities to later periods. However, both the early warning and the consumer's preparations will not heavily reduce these outages costs but rather may relieve some of their impacts and lessen their costs as well and this situation can be seen as exhibited in Figure 4.

In the city of Riyadh, there exist some big homes (mansions) that are equipped with multiple electric equipment such as: swimming pools, water heaters, elevators, entertainment facilities, alarms, sensors, wireless communications. To decrease the cost on these types of houses, standby power sources will be suggested are installed in the premises as sources of energy supply in the event of power outages and energy curtailment in the events of power outages planned by the electric company and can be envisaged in Fig. 5. Both of Figure 5 and Figure 6 assert the rewarding returns of such actions for the consumers, namely, the early warning from the supplier side and the standbys availability from the consumers side.

\section{Developed Mathematical Model}

In general, the most important household outputs that consume electricity are housekeeping duties, nutrition supplies, and social activities. These outputs are domestic activities that are consumed within the household premises and their

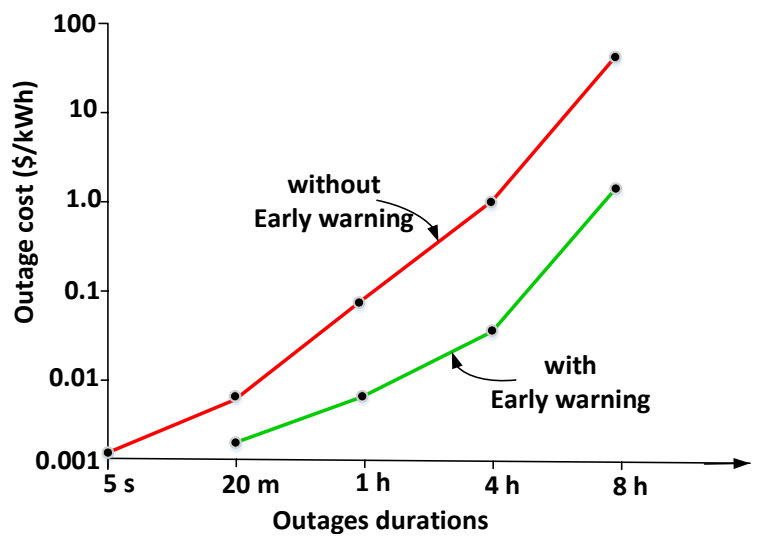

Figure 4. Effect of early warning against outages occurrences. 




Figure 5. Effect of standby availability during outages occurrences.



Figure 6. Limits between Energy consumption cost and load increase.

losses costs due to outages cannot be straightforward or easily assessed in terms of monetary values. In the following analysis, a method to reduce these losses costs will be established through an energy conservation mathematical model.

Now, let the set representing electricity service is defined by the varying load, $L$ for each individual consumer $j$ in a dwelling type $i$ as follows:

$$
L=L_{j i}, j=1 \text { to } m \text { and } i=1 \text { to } n
$$

The load is a function of other variables and the equation may be written as:

$$
L_{j i}=L_{j i}\left(P_{j i}, Y_{j i}, O_{j i}\right)
$$

where $P$ is the type of electrical appliance, $Y$ represents the intensity of energy utilization (domestic activities), and $O$ is an unexpected outage(s) occurrences 
that may affect the load levels.

The energy cost (invoice charge), that the consumer $j$ of dwelling type $i$ pays in regular intervals $(\mathrm{T})$, set by the local electric company, as a consequence of providing the electric service, can be denoted as an Energy Cost $\left(E C_{j i}\right)$ and expressed as:

$$
E C_{j i}=E C_{j i}\left(L_{j i}, T_{j i}\right)
$$

As described in Equation (2), the cost incurred by the residential consumers because of power outages resulting in energy curtailments may be represented as a function of outage size as well as its lasting duration. For the same type, the outages cost designated as $O C_{j i}$ can be expressed as:

$$
O C_{j i}=O C_{j i}\left(O_{j i}, T_{j i}\right)
$$

The energy cost (EC) described in Equation (2) corresponds to such charges (USD/kWh) paid to the utility (local electric company) for the energy delivered and consumed within the residential consumer property. The outage cost (OC) expressed in Equation (3) corresponds to the direct and indirect costs borne by the residential consumer for the kilowatt-hours not delivered because of power outages.

Now, the expressions displayed in both Equations (2) and (3) can be convolved to arrive at the most appropriate net benefit $(N B)$ of electricity consumption that will ensure both service continuity and quality for a residential consumer as follows:

$$
N B_{j i}=\sum_{j=1}^{m}\left[\sum_{i=1}^{n}\left(T B_{j i}-O C_{j i}\right)-E C_{j i}\right]
$$

where $T B_{j i}=T B_{j i}\left(L_{j i}\right)$ is the total benefit of energy consumption in the absence of outages. It is obviously realized from Equation (4) that the consumer will gain a benefit in terms of decreasing his electricity bill and avoiding the costly outages if he utilizes and conserves his energy consumption properly and wisely. The residential sector is urged to adopt specific programs and abide by certain rules for energy conservation (for example, choosing the efficient air conditioners, applying roof and wall insulation, using the energy saver types of lamps, using double-glaze and shaded windows, utilizing the sky light and solar energy, etc.). The change in the net benefit $(N B)$ due to change in consumer behaviour to enhance his energy conservation (i.e. variation in the set of load levels), yields the following equation:

$$
\Delta N B^{l}=N B^{l+1}-N B^{l}
$$

Using Equations (2-4) into Equation (5), the resultant change in net benefit $\triangle N B^{l}$ is given by:

$$
\Delta N B^{l}=\sum_{j=1}^{m} \sum_{i=1}^{n}\left[\frac{\partial}{\partial L_{j i}}\left(T B_{j i}-O C_{j i}^{l}\right) \cdot \Delta L_{j i}^{l}-\frac{\partial C E_{j i}^{l}}{\partial L_{j i}} \cdot \Delta L_{j i}^{l}\right]
$$

Based on the foregoing discussion, a simplified version of Equation (6) can be 
expressed as:

$$
\Delta N B^{l}=-\Delta O C^{l}-\Delta C E^{l}
$$

where,

$$
\Delta O C^{l}=\sum_{j=1}^{m} \sum_{i=1}^{n}\left[\left(\partial O C_{j i}^{l} / \partial L_{j i}^{l}\right) \cdot \Delta L_{j i}^{l}\right]
$$

and

$$
\Delta C E^{l}=\sum_{j=1}^{m} \sum_{i=1}^{n}\left[\left(\partial C E_{j i}^{l} / \partial L_{j i}^{l}\right) \cdot \Delta L_{j i}^{l}\right]
$$

In Equation (7), it is assumed that:

$$
\left|\Delta N B^{i}\right|=\left|\Delta O C^{i}\right|-\left|\Delta C E^{l}\right|
$$

To interpret Equation (8), it could be stated that: "the customer can maximize his net benefits of energy consumption up to the prescribed load limit designated as $\mathrm{L}^{*}$ where exceeding this limit may cause power outages and hence energy curtailment or undesired higher energy cost". See Figure 6.

\section{Outage Cost Estimation by Using Survey Method and Mathematical Model}

In this research, two main approaches were considered and presented. An obvious approach is a rate increase approach, wherein respondents were asked to what extent in tariff rate increase are they are willing-to-pay to avoid outages for various outages durations. The direct worth evaluation approach asked consumers to place a monetary value on the effects of certain curtailments scenarios or to assess the worth to them of not having to experience a curtailment. The average value of the maximum amount per month that the respondents were willing to pay for less severe outages (curtailments) occurrences is based on their average monthly energy consumptions ( $\mathrm{kWh} / \mathrm{mo}$.) and invoice payments (USD/mo.) during Summer season. This approach may suffer due to the difficulty that residential respondents encounter when attempting to give a meaningful answer to direct evaluation questions. This difficulty stems from the lack of respondent experience with markets in which intangible benefits, such as electric service reliability, are exchanged as a commodity. Another approach which has been developed and used is based on a mathematical model. This model can decrease the size of the problem that may be associated with consumer lack of experience in rating the worth of service adequacy and continuity. Estimates results of both approaches are shown in Table 1 and plotted in Figure 7 for comparison. The two curves show some discrepancy which may be ascribed, in the questionnaires results, to the infrequent outages occurrences and subsequent lack of enthusiasm on the part of consumers to respond to outages in buying emergency items or taking any precautionary actions. The model estimates seem to be higher and this also could be attributed to the electricity-dependence weight embodied in the estimate due to the link between the use of energy and the per capita income. 
Both curves demonstrate clearly the time-dependent and the non-linear nature of the outages cost that probably may reach prohibitive limits should outages last and extend for longer durations.

\section{Comparison with Other Similar Studies}

The cost estimation of energy cease as $\$ / \mathrm{kWh}$ for the residential sector, shown in Figure 8, Figure 7 is evaluated for the purpose of this study as well as to be conveniently compared with other similar time durations studies. Figure 7, Figure 8 portrays results of studies conducted in some countries including Kingdom of Saudi Arabia (KSA) study. The KSA results, compared with those other results, seem to yield rather average estimates. This can be interpreted as the methodology is based on the actual payable tariff. The Saudi government

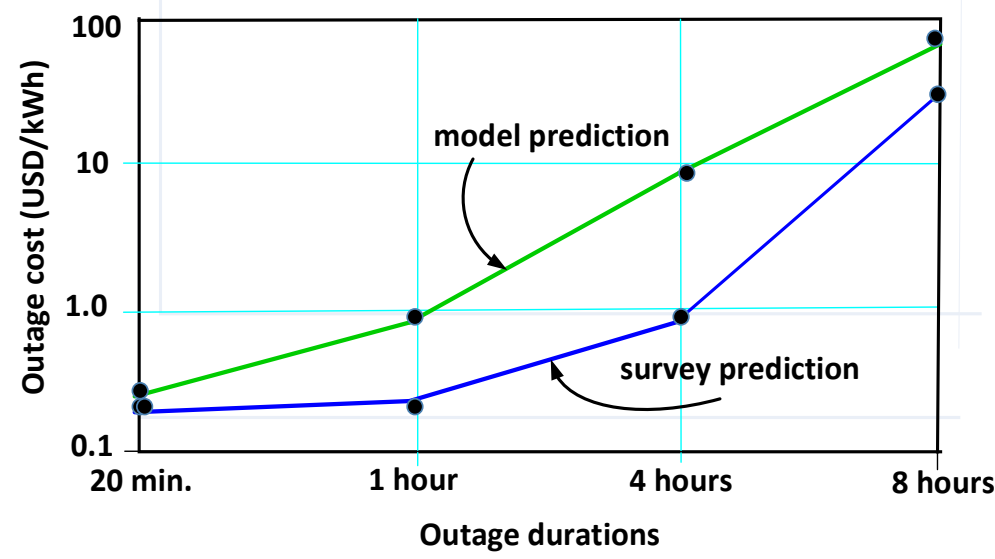

Figure 7. Variation of outage cost vs. outage durations.

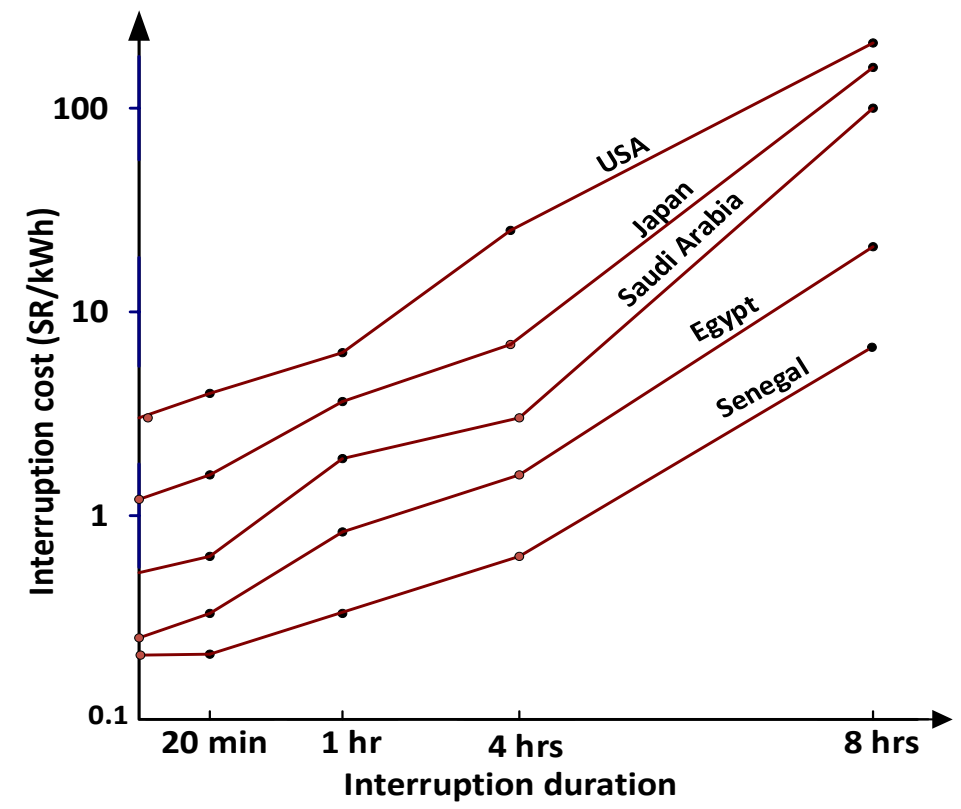

Figure 8. Comparison of Saudi Arabia City outages cost with other world countries. 
started to freeze the subsidiaries to the electric sector and the customers pay the total tariff cost. The noticeable diversities in these estimations seen in the Figure 6 , Figure 8 can be attributed to variations in systems characteristics, the nonlinear nature of outages costs, and the different modeling techniques employed.

\section{Conclusion}

This work assesses energy curtailments due to severe electric power outages that result in energy curtailments. Two approaches have been developed and implemented. The results reveal that these outages will deprive consumers from the usage of certain essential appliances, hinder domestic activities, hamper social ceremonies and events cause food spoilage, and adversely impact the health of vulnerable individuals. The adverse effects of these outages are estimated with respect to their lasting duration. This work can form essential help and useful tool for system planners that enable them to incorporate consumers' costs in their planning processes regarding energy conservation, tariff structure, and reliability-cost tradeoff assessment.

\section{References}

[1] Lawton, L., et al. (2006) A Framework and Review of Customer Outage Costs: Integration and Analysis of Electric Utility Outage Cost Surveys. Lawrence Berkeley National Laboratory.

[2] Vivien, Jean, E.P. and Woodon, Q. (2000) Energy Consumption and Income: An Inverted-U at the Household Level. World Bank.

[3] Hamachi, K. and Eto, H. (2006) Cost of Power Interruptions to Electricity Consumers in the United States. The International Journal of Energy, DOE, USA.

[4] Manikya, R., Prasad, P. and Tulasi, R. (2010) Consumer Outage Cost Evaluation in Electric Power Systems. Journal of Engineering and Applied Sciences, 5.

[5] Layton, D. (2006) The Cost of Power Curtailments to the Residential Consumers. School of Public Affair, University of Washington, Applications of Simulation Methods in Environmental and Resource Economics.

[6] Snead, B. (2006) Energy Efficiency and Conservation in the Residential, Commercial and Residential Sectors. Final Report, Kansas State University, USA.

[7] Benders, R. (2006) New Approaches for Household Energy Conservation: In Search of Personal Household Energy Budgets and Energy Reduction Options. Energy Policy, 34, 3612-3622. https://doi.org/10.1016/j.enpol.2005.08.005

[8] Marshall, M. (1987) Social-Psychological Correlates of Household Energy-Conservation Activities. Ph.D. Thesis, Claremont Graduate School.

[9] McMakin, A., et al. (2002) Motivating Residents to Conserve Energy without Financial Incentives. Environment and Behavior Journal, 34.

[10] Fuji, E.T. (1989) Model of Household Electricity Conservation Behavior. Land Economics, 60

[11] Yoshiyuki, S. (2007) Evaluation of City-Scale Impact of Residential Energy Conservation Measures Using the Detailed End-Use Simulation Model. Energy, 32, 1617-1633. https://doi.org/10.1016/j.energy.2007.01.007

[12] Abrahamse, W. (2005) A Review of Intervention Studies Aimed at Household 
Energy Conservation. Journal of Environmental Psychology, 25, 273-291. https://doi.org/10.1016/j.jenvp.2005.08.002

[13] Park, H.-C. and Heo, E. (2007) The Direct and Indirect Household Energy Requirements in the Republic of Korea from 1980 to 2000. Energy Policy, 35, 2839 2851. https://doi.org/10.1016/j.enpol.2006.10.002

[14] Ghaddar, N. (1998) Energy Conservation of Residential Buildings in Beirut. International Journal of Energy Research, 22, 523-546. https://doi.org/10.1002/(SICI)1099-114X(199805)22:6<523::AID-ER373>3.0.CO;2-R

[15] Taniguchi, A. (2007) Effectiveness of Energy Conservation Measures in Residential Sector of Japanese Cities. http://www.ibpsa.org/proceedings/BS2007/p356_final.pdf

[16] Xu, P. (2006) A Case Study of Upgrading an Existing Residential Building Relating to Energy Conservation in China. Journal of Building Physics, 20, 116-131.

[17] Helseth, A. and Holen, A.T. (2008) Impact of Energy End Use and Customer Interruption Cost on Constrained Distribution Networks. IEEE Transactions on Power Delivery, 23, 1419-1425. https://doi.org/10.1109/TPWRD.2007.909215

[18] AF-Mercados Consultant (2017) The Effect of Power Interruptions on the Kingdom Economy. Final Technical and Financial Report Prepared for the Saudi Electricity Company, Riyad, Contract No. 11182017/00.

[19] Wooa, C.K., et al. (2016) Residential Outage Cost Estimation: Hong Kong. Energy Policy, 72, 204-210. https://doi.org/10.1016/j.enpol.2014.05.002

[20] Rastegar, M. and Fotuhi-Firuzabad, M. (2015) Outage Management in Residential Demand Response Programs. IEEE Transactions on Smart Grid, 6, 1453-1462. https://doi.org/10.1109/TSG.2014.2338794

[21] Munasinghe, M. (1980) Costs Incurred by Residential Electricity Consumers Due to Power Failures. Journal of Consumer Research, 6, 361-369. https://doi.org/10.1086/208779

[22] Shao, S., Pipattanasomporn, M. and Rahman, S. (2013) Development of Physical-Based Demand Response-Enabled Residential Load Models. IEEE Transaction on Power Systems, 28, 1-8. https://doi.org/10.1109/TPWRS.2012.2208232

[23] Kumar, D., Sinha, S., Garg, A. and Vijay, A. (2012) Estimating Electricity Supply Outage Cost for Residential and Commercial Customers. North American Power Symposium (NAPS), Champaign, 9-11 September 2012, 1-6. 